\title{
Employee participation in organizational change: A case of Tesco PLC
}

\author{
Adam Cassia Awadari ${ }^{1}$, Shamsa Kanwal ${ }^{2}$ \\ Research Consultant \& Author It GH ${ }^{1}$, Queen Margaret University ${ }^{2}$, \\ kingcacia@gmail.com ${ }^{1}$, shamsa_kanwal47@ hotmail.com²
}

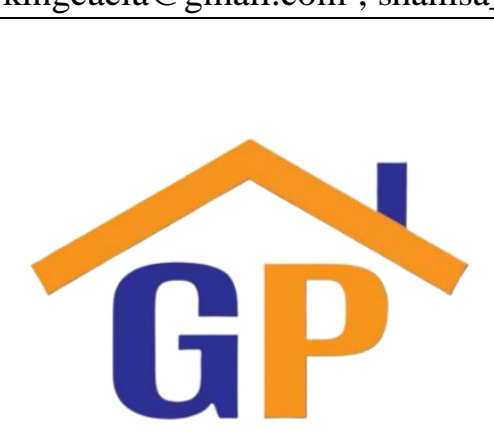

Article History

Received on 21 November 2019

$1^{\text {st }}$ Revision on 22 November 2019

$2^{\text {nd }}$ Revision on 25 November 2019

$3^{\text {rd }}$ Revision on 30 November 2019

$4^{\text {th }}$ Revision on 5 December 2019

$5^{\text {th }}$ Revision on 9 December 2019

$6^{\text {th }}$ Revision on 15 December 2019

Accepted on 16 December 2019

\begin{abstract}
Purpose: The research work attempts to identify some of the challenges and difficulties that were associated with the recent technological changes in Tesco PLC (from cashier to customer self-checkout) and its related effect on employee attitude and performance.
\end{abstract}

Research methodology: The research is a case study type; a convenient sampling method was used for selecting the sample for the study. The sample chosen for this research comprises of 3 store managers and 13 checkout staff of Tesco Express Kilburn branch.

Results: The findings revealed that management and customer assistants were well educated and well aware of the on-going strategic changes by management. Management was also aware of the vital role effective communication plays in the overall success of the program but communication had not been very impressive during the initial stages. It was also revealed that customer assistants developed a negative attitude, due to the fear of job insecurity, they had the impression the self-checkout was being implemented to replace their roles.

Limitations: A generalization of the phenomenon across the organization's portfolio cannot be drawn on grounds of sample size representation. It is also acknowledged that using only one retail store for the research was a significant limitation covering more stores would have added considerable information to the findings.

Contribution: This study has contribution for the formulation of policies and programs that should consider the inclusion of employees as major stakeholders in the design and planning of any organizational change.

Keywords: Change management, Employee, Participation, Attitude, Performance

How to cite: Awadari, A. C., \& Kanwal, S. (2020). Employee participation in organizational change: A case of Tesco PLC. International Journal of Financial, Accounting, and Management, 1(2), 91-99. https://doi.org/10.35912/ijfam.v1i2.93

\section{Introduction}

In today's competitive world, change happens in every organization. The challenge faced by most organizations is how to effectively implement and manage the change they seek successfully. Most change initiations have shown results of employee resistance at various stages of implementation due to less employee involvement in the change process. The world's competitive business environment is growing faster than ever. The innovation and creativity of an organization from one part of the world spread faster to other parts of the world within days or even within a few hours. Organizations in this regard are putting up their best efforts to improve performance continuously to stay ahead of competitors. These organizations are adopting new methods and introducing different ways to create a 
center of attention to customers and to make them effective and competitive. For organizations to align themselves with the changing business environment and to survive it has become imperatively necessary for businesses to effectively implement and manage change both within and outside the organization. According to Stanleigh (2008), "the majority of change implementation strategies fail because the organization's management does not engage employees in the development process and do not allow adequate time for change to set". The engagement and involvement of employees and all parties in the process are vital to the success of the process and strategy. Some of the reasons for the failure in the change strategy can be lack of communication across the board, failure in defining the objectives of the need for the change, inexperience in the scope and complexity, technical issues and project management issues. When the rate of change from the external environment of a business exceeds the rate of change within an organization, they are signs of the end time for the business. It is therefore imperative for organizations who seek success to keep pace with changes in the external environment of the business. Story (2007) described that organizational change metamorphosis is the main response to some important threats arising outside of the organization. Gilgeous (1997) also illustrated that organizational changes take place both in reaction to business and economic events. According to the Department of Trade and Industry (1994) "Winning UK companies are led by creative thinkers, eager champions of change".

Change needs to be considered by managers at all levels. It is important to think of the grounds for the need for change and what needs changing. For instance, the main causes of change can be divided into two groups' external causes of change, which can be customer expectations, technology change, market place changes, quality and standards, government legislation, competitor activities, and political values or changes in the economy. The internal change in an organization happens as a result of the change in management culture, system, structure, philosophy, and structure of control and power (Gilgeous, 1997). The main purpose of the paper is to explore how organizational changes are initiated, implemented and managed. The specific objectives, therefore, seek to:

- Examine the nature of organizational change and the level of employee involvement and participation during the implementation stages.

- Explore and examine some of the policies, practices, and models used by management during the initiation and implementation process.

- Determine the impact of organizational change on employees' attitudes and performance.

- Unearth a possible conflict or complementarities between management and employees during the change process

To effectively find answers to the research objectives and offer the best way to obtain research solutions, it was also important to look at the following research questions:

1. What is the organizations' policy consideration for the involvement and participation of employees at the decision and formulation stages?

2. What are some of the strategies and processes used by management during the implementation stages?

3. What roles do employees play during the implementation processes?

4. What is the impact of organizational changes on the attitude and performance of employees?

\section{Literature review and hypotheses development}

\subsection{Change management: Definition and extent}

Historically, there has been a wide range of research and literature on change management most of the literature has tried to address the issue of organizational change phenomenon, by recognizing that organizations, attempting to implement change usually go through a systematic evolution through multi-phase processes. Lewin (1951), a pioneer in the analysis and understanding of organizational change, stressed the need in providing an initial conceptualization of organizational change initiative during change implementation, he laid further emphasis on the fact that the implementation should be clustered as the unfreezing, moving and refreezing stages. Judson (1991) on the other hand, suggested a more contemporary model, his approach identifies a five-phase process of change implementation. 
These include; analyzing and planning for the change, communicating the change, gaining acceptance of new behaviors, changing from status quo to the desired state, consolidating and institutionalizing the new state.

Cameron and Green (2004) wrote that change from an organization context means the shifting of an organization from one state to another. They further emphasized that one of the challenging variables of an organization is control over what happens within the organization and its external environments, for organizations to be able to survive this phenomenon, there is the need for organizations to take on fundamentally new ways of management. Similarly, Hiatt and Timothy (2003) also explained that change comes in many forms. Its span can vary and this can affect the functioning of an organization either in parts or the whole organization. Change can also vary in intensity which can lead to small or incremental modifications. In some circumstances, it would require abandoning existing ways of organization functions and procedures. Jick (1993) posited that organizational change whether planned or unplanned can contribute to pressures and forces from both the internal and external environment of an organization.

Organizational change has taken a center stage of management of recent times and now regarded as a dominant and constant feature of organizational life. It is indeed undoubtedly a fact that change in today's organizations is occurring at an overwhelming rate. Storey (2007) in his research identified that organizational change does occur as a response to the threat or opportunity arising from the outside of a business environment. According to Gilgeous (1997), "Changes within an organization take place both in response to business, managerial perception, choice, and actions. Managers in this sense see events taking place that, to them, signal the need for change". The unprecedented nature of change in today's fast-shifting economies is evident in the pervasive nature of lives as human beings. These also affirm the fact that change is a fact of life within the human system. Recent researches have indicated that this fact has become a concern for management as well. Paton and Mccalman (2000) described that the reason for the rapid change in trend is as a result of technological breakthroughs in distribution, information, and communication systems. Siegal et al. (1996) raised the concern that the world is changing into an era where the geopolitical precincts that have been the trademark of our history are gradually fading. Present-day organizations are faced with the virtual challenges of global and domestic change as they attempt to adjust to the demand of the markets.

\subsection{Role of management}

Management plays a critical and important role in implementing change. 'Implementation' in this context is the processes or recipes that are required for a change initiative to be possible or effective. Kirton (1980) indicated that "it is equally clear that managers increasingly play a vital role in implementing change". Storey (2007) in his research concludes that managers have an active role to play when it comes to decisions on organizational change and that, these decisions involve determining the organizational capability through informed and sustained logic and assumptions. Bennis (1994) also wrote that the prerequisite ingredient of change management is 'guided vision'. The manager should have a comprehensible plan and direction of what he/she wants to accomplish; professionally, personally and the strength to persist in the face of setbacks or the event failures.

Organizational change is currently a focus of attention among academics and practitioners across the world. Global issues and trends such as privatization, public sector reforms, mergers and acquisitions, the influence of Multinational corporations, population migration, poverty and advances in Information and communication technology. Present major challenges to those charged with equipping people in organizations to adapt and flourish in these turbulent times. Given these challenges, it is natural for managers to search for information as to how best to manage this change. It is notable that, in recent years the scope of organizational change literature has rapidly expanded. There is no wide-scale recognition that effective organizational change practice is inextricably associated with organizational performance and this recognition has created a hunger for theories and models as to how best to manage this organizational change in different settings (Rees, 2008). Similarly, researchers such as Palmer (2004) go even further by suggesting three basic steps for managers, he reiterates that these steps can be used to determine either the state of readiness exist or not. The first of these is making an analysis and compilation of the foremost activities that are 
ongoing; budget allocation for the change implementation, employees' time and awareness. Secondly, there is also the need to allocate the level of effort that each of these activities would involve. These provide for an early assessment of the organization's capabilities towards the change implementation and the consideration of the impact of the change implementation on the organization. These concepts suggest that making an initial assessment of the organization's capabilities from an internal-external perspective gives management a widespread and proactive viewpoint of the organization. It is further noted by Paton and McCalman (1992) that this would require continuous support of management from both the initial and final phases of the change implementation. It produces an attention-grabbing insight into the evolution of change in an organization as well as an understanding of how employees respond to change initiation. Cook et al. (2004) also wrote that the engagement of management in the process is vital in all stages of the implementation to sustain the change in the organization. Their research further points out the role management can play during the implementation stages: The 'set off' stage, this requires the management to identify the need of stakeholders (staffs) through a deliberate formulation of opportunities rather than threats or crises. The 'Vision stage' there is also the need for management to align the vision of the organization in the implementation process through effective communication of all parties involved. The 'Conversion stage' through the change implementation process there is also the need to motivate and mobilize support in the organization for the new vision. This helps in dealing with the trigger of the change implementation. The 'Maintenance and Renewal stage' involves identifying how changes are sustained and enhanced through alterations in attitude, values, and behaviors.

Smith (2005) also identified that management needs to show commitment to the implementation process as well as show indisputable commitment to the provision of opportunities to all those it may concern by involving them in the decision making. Management should not only be the enforcers but they must illustrate this through the organization culture. They should acts as agents of the intended change by fostering the provision of opportunities for employee involvement. Management should provide the solid underpinning for fostering change in every organization, through motivation and by making all stakeholders feel they are a part of the change management rather than making it look as if it is being imposed on them. The right way to do this is by helping employees to undoubtedly see their roles and contribution, this goes a long way in building their confidence and commitment to the change process, before, during and after the change have been implemented. Creating an understanding among employees about the need for the change and reasons in the early stage encourages them to be committed and willing towards this change process.

\subsection{Impact of organizational change on employee's attitude and performance:}

The willingness and readiness of employees towards the change process are vital in the overall success or failure of the change every organization seeks. Human actions are focused on the satisfaction of their needs which determines the person's attitude. It is therefore relevant to establish those needs of employees that drive them towards the change process (Alas and Vadi, 2006). The success of organizational change and development efforts is positively correlated with the extent to which these efforts activate an individual's internal resources. The integration of individual and organizational needs should be achieved to internalize the need for change. It is widely believed that the attitude of an individual control the person to do things in a particular manner under certain circumstance. According to Cooper and Croyle (1984), the cultural background of an individual replicates the belief they hold at both the organizational and societal levels. Secord and Beckman (1969) in their research also reiterated that the attitude of an individual is a reflection of their belief and predisposition towards various facts of their environment. Arnold et al. (1995) described that "attitudes reflect a person's tendency to feel, think or behave positively or negatively. According to Elizur and Guttman (1976), a person's attitude toward change depends on certain factors similar to a person's: cognitions about change, sentimental reactions to change, and the person's behavioral tendency towards change. Other researchers also contributed to this by indicating that, individual response to change could vary and can be classified as strong positive and strong negative attitudes. In other words, strong negative attitudes can have a detrimental effect on organizational change. What is worth noting is that depending on the individual attitude, change implementation could be met with 
excitement and happiness or anger and fear while employee's response to it may range from positive intentions to support the change to negative intentions to oppose it.

Most employees' perception of organizational changes means a change in the organizational culture and routines; as a result, it can create uncertainties among employees leading to a potentially negative and positive fraught outcome. Major organizational change implementations interfere with the organizational culture and life with regards to their group precincts, interpersonal relationships, reporting lines, work unit status and societal identities coupled with their group associations. (Armenakis and Bedeian, 1999). Shyni and Thattil (2005) in there research acknowledged that the reaction and attitude of employees towards change is influenced by certain traits such as self-worth and buoyancy and perceived control. Further studies have identified that these traits control the employee's acceptance of the change. Wanberg and Banas (2000) echoed this by also suggesting other traits associated with employees coping with change. They described that these factors can be measured by the locus of control, feeling of self-efficacy, self-esteem as well as risk tolerance. According to Oreg (2006), the disposition of some employees has an effect and influence on the reaction of other employees' responses and attitudes towards organizational change. It is undoubtedly a fact that the positive attitude of employees towards change in an organization forms the bedrock of the success of the whole process. Existing literature on change management only provides frameworks and methodologies on how to manage change and the need to incorporate change management. However, $70 \%$ of most change initiatives fail because most management fails to recognize the importance of employees' resistance and the development of negative attitudes towards organizational change which affects their morale, productivity, and turnover intentions (Vakola and Nikolaou, 2005; Beer and Nohria 2000).

\section{Research methodology}

The research is a case study type; it is believed that this research strategy will enable the concentration on the specific aspects of the investigation. It is also believed that using a case study would allow for a detailed investigation of the issues under study. According to Traver (2001), the case study type is suitable for research intended to investigate an in-depth phenomenon, it also allows for focusing on a single case under investigation as well as contextual matters. However, it has its limitations, the population under study is mostly small in nature; hence it cannot be used as a generalization of a phenomenon or on grounds of sample size representation.

The convenience sampling technique was employed for the inclusion of respondents in the frame. Saunders et al, (2003), described that this technique is appropriate for research that intends to obtain samples fast. It involves those cases which are easiest to obtain for the sample. The technique is less time consuming, the sample frame is readily accessible and less expensive. The technique has its shortcomings as a non-probability sampling technique compared to probability sampling. Most researchers argue that this technique lacks generalization and does not truly represent a population. To reduce biases, all the respondents were carefully selected and screened through a pilot study before being included in the sample frame. The sample chosen for this research comprises of 3 managers and 13 checkout staffs of Tesco Express Kilburn branch out of a sample size of 29 at the time of the research. The researcher believes that carefully selecting respondents who best fit for inclusion using the convenience sampling technique would reduce time and financial constraints.

Questionnaires were used for the collection of the raw data for the research. Both close-ended and open-ended questionnaires where used. This method was appropriate to elicit sufficient information that was needed. They were specifically designed to elicit the employees' attitude towards accepting change, there understanding of change and the role they play during organizational change. The managers' questionnaire was also designed to focus on how organizational changes are implemented in-store, the procedure for implementing change (employee participation, communication, motivation and possible barriers of change implementation). The advantage of using this method was that all the respondents could read and write, less expensive and suitable. 


\section{Results and discussions}

\section{Role of management during organizational change}

Previous literature review revealed that organizational change is essential and a common feature for the changing world. Change happens at different levels whether in smaller or bigger organizations for them to remain competitive. Change is therefore seen as indispensable for organizations' survival. Any organization that does not change itself with time cannot survive or exist in the long run (Storey, 2007; Burnes, 2000). This necessitated the need to elicit from both the managers and customer assistants about their perception of the need for organizational change. The study revealed that most of the respondents were aware of the need for organizational change and were in support of change initiation and implementation. To find out whose responsibility it was in initiating and implementing changes in the store. The customer service assistance unanimously agreed it was the role of management. The response was found to be consistent with the literature review that, management plays a very important role in the initiation and implementation of change in every organization (Kirton, 1980; Bennis, 1994; Storey, 2007). This further goes to assert to the fact that, managers are the means of making a change implementation a success or a failure. Manager's plan and put change into practice according to the needs of their organization and customers or their clients.

It was also identified that the management of the store was fully aware of how to implement change systematically by using particular models or techniques. Most of the decisions on changes in the store are made from the head office, they are mostly executives' decisions on what should be changed and how it should be done. It is the role of management to communicate any changes to the staff and to put in place all necessary resources and mechanisms in place for its effective implementation.

\subsection{Training before or during implementation of change}

It emerged from the literature review that, budget allocation, employees' time and awareness should be the prerequisite for implementing change in any organization (Palmer, 2004). Management was asked about some of the prerequisites preparations they put in place before the implementation of changes in the store, in terms of budget lines, training, staff development, and communication. The general manager indicated that on-job training, workshops, group discussions, and customer feedback sessions, refresher courses are mostly done before, during and after making any changes in store. Also, the management was always available to provide further assistance to customer assistance when they encounter any difficulties in the operations and demonstration of the new systems, but most of the customer assisted indicated that to a larger extent they relied on the help of their colleagues for further assistance most of the time.

It also emerged that, resources are provided for the effective running of the day to day of the store but there was no specifically allocated budget or a separate budget for training. They mostly rely on the services of experienced staff that pass on the training to the shop floor staff. It was also realized that, on most occasions, staff could go to work to either continue with their usual day to day routines or be told to do things differently, depending on the directives from the top management or executives.

\subsection{Importance of effective communication and employee participation in the change process}

Employee motivation and involvement during the initiation and implementation stages go a long way to prevent negative response and resistance to the efforts. Also, from the literature review, it was postulated that employee motivation and involvement in the process can prevent a negative response and resistance to the efforts (Armenakis \& Bedeian, 1999). The response from both the management and customer assistance showed a unanimous affirmation of their involvement and participation in the implementation process. The organization also has in place regular feedback and survey where they assess how the employees are cooping and getting on with the new changes. The results showed that the organization's management sees the involvement of employees in the decision process as a vital part of the success of the change process. The study also revealed that employees' participation was among one of the priorities of management. This was seen as a positive step as this is the way through which fears and doubts of the employees can be addressed and it is also important to convey the right messages to the employees throughout the change process. This was found to be consistent with Paton 
\& McCalman (2000) suggestion that communicating the change process from the onset is vital if the change has to be successful.

\subsection{Impact of change on job insecurity}

Most employees' perceptions of organizational changes mean a change in the organizational culture and routines, as a result, can create uncertainties among employees leading to a potentially negative and positive fraught outcome (Kitchen and Daly, 2002). From the responses of the customer assistants, most of them had problems during the introduction of the self-scan system; they had difficulties with the new checkouts procedures and self-scan software. Some of them could not cope with the new changes in the system as they could not understand the new technology. Some of the customer assistants were uncertain about their future because they thought in due course most of their jobs would be replaced by the self-scan system. This goes to also prove the point that changes in organizations lead to a reduction in morale, uncertainty, and job insecurity scare among employees.

\subsection{Impact of organizational change on employee's attitude}

There was a significant difference in the response from managers and customer assistants regarding the impact of change on employee's attitudes. While most of the customer assistants held that changes in organizations can lead to a negative attitude, the response from management, on the other hand, indicated a contrary. The management response collaborates with the literature which revealed that management is most interested in the success and profits. For instance one of the duty managers did make references to the fact that some changes that were implemented in the store two years ago had increased the confidence of the staff, sales at the store went up during the period. The customer assistants, on the other hand, perceived some of the changes being put in place as threats to their jobs (job insecurity). They indicated that there was always pressure from management on staff to meet targets which they perceived as a displacement from their set patterns of daily work schedule. This agreed with Beer and Nohria et al. (2000) assertion that organizational change impacts either positively or negatively on an employee's attitude which can have a direct effect on the change process.

\section{Conclusion}

It was revealed that open discussions, employee feedback, and regular surveys were used as a channel for employee's opinions and suggestions. Management was fully aware of the importance of employees' involvement in the decision and implementation process but did not follow any particular model in implementing these changes. It was further identified that most of the customer assistance was nervous and uncertain about their future because they were scared of the fact that their services were gradually being replaced by the introduction of the self-scan. It was also evident that there was no effective communication from top-down most of the change initiatives came us a surprise to the employees. Employees could go to work the following day and be told of a new directive from top management effective the same day. Involving the employees during the decision-making stages would have also gone a long way to reduce the myth and uncertainties. It can, therefore, be concluded that a lack of effective communication, employee involvement, and participation at the decision and initiation stages had a negative effect on the attitude of employees.

Future implementations could look at ways of involving the employees not just at the implementation stage but at the decision and initiation stage to improve the implementation process. This would go a long way in changing the customer assistant's negative or resistant attitude. This can be done by, incorporating in the company change strategy, the participation and involvement of employees in the initiation and implementation process. Where it is not possible to involve the employee's at the decision stage, effective communication from the onset is vital. As part of the organization's policy, regular team and group discussions usually take place in-store. Such group discussion sessions or group meetings can also be used as a platform to address some of the difficulties, myths, and scare of some of the employees during the initiation and implementation process. This would also improve their performance as well as boost their morale. 


\section{Acknowledgement}

In carrying out this research, many people offered their invaluable support in various ways. We are grateful to the management and staff of Tesco Express Kilburn branch for taking some time off their busy schedule to participate in this research. Finally, to the International Journal of Financial, Accounting, and Management (IJFAM) for allowing us space and adding value to this article.

\section{References}

Alas, R., and Vadi, M. (2006). The employees' attitude and their connections with the organizational culture in the process of change in Estonian organizations. Baltic Journal of Management, $1(1), 49-66$

Armenakis, A., \& Bedeian, A. (1999). Organizational change: A review of theory and research in the 1990s. Journal of Management, 25(3), 293-315.

Arnold, J., Cooper, C., \& Robertson, I. (1995). Work psychology: Understanding human behavior in $\backslash$ the workplace. London. Pitman Publishing.

Beer, M., \& Nohria, N. (2000). Cracking the code of change. Harvard Business Review, 78 (2), 13341.

Bennis, W. (1994). On becoming a leader. Reading. Addison-Wesley.

Burnes, B. (2000). Managing change: A strategic approach to organizational dynamics. Third Edition. Harlow-FT. Prentice-Hall.

Cameroon, E., \& Green, M. (2004). Making sense of change management: A complete guide to the models, tools, and techniques of organizational change. London. Kogan Page.

Cooper, J., \& Croyle, R. T. (1984). Attitude and attitude change. Annual Review of Psychology, 35 (1), 394-426.

Cook, S., MaCaulay S., and Coldicott H. (2004). Change management excellence: Using the four intelligence for successful organizational change. London. Saxon graphic Ltd

Department of Tradeand Industry. (1994). How the best UK companies are winning. London. DTI.

Elizur, D., \& Guttman, L. (1976). The structure of attitudes toward work and technological change within an organization. Administrative Science Quarterly. 21 (4), 611-622.

Gilgeous, V. (1997). Operations and the management of change. England. Pearson Education Limited.

Hiatt J., and Creasey T. (2003). Change management: The people side of change. Colorada. Prosci.

Jick, T. D. (1993). Managing change: Cases and concepts. Irwin. Homewood IL.

Judson, A. (1991). Changing behaviors in organizations: Minimizing resistance to change. Cambridge. Basil Blackwell.

Kirton, M. (1980). Adaptors and innovators. Journal of Human Relations, 3, 213-24.

Kitchen, P., \& Daly, F. (2002). Internal communication during change management. Corporate Communications Journal. 7 (1), 46-53.

Lewin, K. (1951). Field theory in social science: Selected theoretical papers. New York. Harper and Row.

Oreg, S. (2006). Personality, context, resistance to organizational change. European Journal of Work and Organizational Psychology, 15 (1), 73-101.

Palmer, B. (2004). Overcoming resistance to change. Quality Progress. 37 (4), 35-40.

Paton, A. R., and McCalman J. (1992). Change management: A guide to effective implementation. London. Chapman Publishing Ltd.

Paton R., and McCalman J. (2000). Change management: A guide to effective implementation. London. SAGE publications LTD.

Rees, J. C. (2008). Organizational change and development: Perspectives on theory and practice. Journal of Business Economics and Management, 9 (2), 87-89.

Secord, P., and Beckman, C. (1969). Social psychology. New York, N.Y. McGraw-Hill.

Siegal, W., Church H. A., Javitch M., Waclawski J., Burd S., Bazigos M., Yang F T., Rudolph A. K.,

Burke W. (1996).Understanding the management of change: An overview of the manager's perspectives and assumptions in the 1990s. Journal of Organizational Change Management, $9(6), 54-80$.

Stanleigh, M. (2008). Effecting successful change initiative: industrial and commercial training, 40 (1), 34-37, Emerald Group Publishing Limited. Retrieved from 
https://doi.org/10.1108/0019785081084162

Storey, J. (2007). Human resource management: A critical text ( $3^{\text {rd }}$ ed.). United Kingdom. Thomson learning.

Shyni K., and Thattil G. (2005). Change management vis-vis human resource management. New Delhi. Discovery publications.

Smith, I. (2005). Achieving readiness for organizational change. Library Management, 26 (6), 408 412.

Saunders, M., Lewis, p., \& Thornhill, A. (2003). Research method for business students (3rd ed.). New York: Prentice Hall

Travers, M. (2001). Qualitative research through case studies. London. Sage.

Vakola, M., and Nikolaou, I. (2005). Attitudes towards organizational change: What is the role of employee's stress and commitment. Journal of Employee Relations, 27 (2), 160-174.

Wanberg, C. R., and Banas, J. T. (2000). Predictors and outcomes of openness to changes in reorganizing workplace. Journal of Applied Psychology, 85 (1), 132-142. 